\title{
Stratospheric tropospheric wind profiling radars in the Australian network
}

\author{
Bronwyn K. Dolman ${ }^{1,2^{*}} \mathbb{0}$, lain M. Reid ${ }^{1,2}$ and Chris Tingwell ${ }^{3}$
}

\begin{abstract}
The Australian Government Bureau of Meteorology completed the installation of a network of 9 new wind profiling radars across mainland Australia in 2017, which complement an existing network of 5 profilers and 5 research systems. This results in a network of 14 operational, and 19 total, profilers across Australia and Davis Station in Antarctica. Four of the new profilers are higher power stratospheric tropospheric systems, designed to measure winds from near ground level to the tropopause, and maintain the upper air network in Australia where sonde launches are no longer available. Wind measurements in the near field of the radar are demonstrated to be both possible and accurate by comparison with co-located radiosondes. Quality control procedures producing winds of sufficient accuracy for presentation to forecasters and ingestion into global numerical weather prediction models are described. The Australian network data are available on the global telecommunications system and are currently being ingested into all major models. First results from impact studies on forecast error reduction in the Australian Community Climate and Earth Systems Simulator show remote stations have the greatest impact.
\end{abstract}

Keywords: Stratospheric tropospheric wind profilers, Wind measurements, Forecast error impacts

\section{Introduction}

The Australian Government Bureau of Meteorology (AGBoM) installed the last of nine new wind profiling radars (WPRs) across mainland Australia in 2017. These new systems complement an existing AGBoM network of 5 legacy WPRs which have recently undergone software and minor hardware upgrades, resulting in 14 operational systems. All but 2 of these systems are located on Bureau operational sites, while Cairns and Mackay are installed in the center of horse racing tracks. The legacy network and 5 of the new WPRs are boundary layer profilers (BL/BLP), intended to provide winds from $300-\mathrm{m}$ to $3-\mathrm{km}$. The remaining 4 new WPRs, and the subject of this paper, are stratospheric tropospheric profilers (ST/STP), intended to provide winds from $500 \mathrm{~m}$ to $16 \mathrm{~km}$. Profiler locations and instrument types were selected in an effort to maintain the Australian upper air network, while moving to automated operation at some AGBoM sites. At some sites, particularly where radar tracked sondes

*Correspondence: bdolman@atrad.com.au

${ }^{1}$ ATRAD Pty Ltd, Thebarton, Australia

Full list of author information is available at the end of the article were launched, profilers replace this equipment, while at others, particularly where auto-sondes are installed, the profilers provide complementary observations. An additional aim was for the network to run at an amortized cost of $25 \%$ of the cost of operating radiosondes over a period of 10 years. This figure has been easily met and is drastically reduced when costs are considered per profile, as the wind profilers run continuously as compared to two flights per day. Network design considerations called for robust systems capable of operating in remote and harsh Australian environments with very low maintenance, to be both modular and scalable to meet changing requirements over time, for system operation which is not susceptible to single-point failures, and a commonality of hardware across both ST and BL systems to minimize spares storage and user training requirements.

As is commonly used by other weather agencies, the AGBoM STPs use the Doppler beam swinging (DBS) technique, while the BLPs differ and employ the spaced antenna technique and the full correlation analysis (FCA) (see Dolman and Reid 2014). All 14 AGBoM WPRs, regardless of type or build standard, operate in the VHF band at $55 \mathrm{MHz}$. In addition to the 14 AGBoM WPRs, 
there are 5 research/quasi-operational systems operated by ATRAD Pty Ltd, Mt Isa Mines and the Australian Antarctic Division, which also run at $55 \mathrm{MHz}$ and are a mix of ST and BL systems. This makes a total of 19 WPRs operating across Australia and Davis Station in Antarctica. System locations and types are shown in Fig. 1.

VHF profilers operating near $50 \mathrm{MHz}$ are ideal for continuous wind estimates, as they are insensitive to radar returns from birds, bugs and bats and can simultaneously detect Bragg scatter from clear-air refractive index fluctuations and Rayleigh scatter from hydrometeors in precipitation conditions (see, e.g., Sato et al. 1990; Dolman and Reid 2013). A perceived limitation at lower VHF, particularly for radars intended to sample winds to as high an altitude as possible, is the use of large transmitter powers and physically large antenna arrays. While this may be true historically, technological developments have led to systems of manageable size utilizing both Doppler and FCA wind measurement techniques. Historically, a corollary to using high powers and large antenna arrays is a difficulty in sampling the boundary layer, due to problems with receiver ringing, poor transmit/receive switch recovery and ground clutter (see, e.g., Ecklund et al. 1988; Vincent et al. 1987). It has also been considered that results from large antenna arrays are only usable in the farfield of the antenna array (Ecklund et al. 1988), where this paper will demonstrate near-field wind estimates are both possible and accurate.

Crochet et al. (1993) reimagined the ST radar concept and developed a smaller lower VHF Doppler system capable of sampling the lowest part of the atmosphere, and the continuous research and development in both software and hardware has led to the operational systems discussed here (see Reid et al. 2005; Reid 2009a, b; Reid and Dolman 2010; Dolman and Reid, 2011a, b, c), where WPRs must provide reliable and accurate wind measurements, updated with high temporal resolution. Measurements from as close to the ground as possible in the boundary layer, up to the tropopause, with sufficient spatial resolution to identify features such as jets are very important. In this paper we discuss the development, implementation and performance of the operational ST radars. For a description of the BL systems, refer to Dolman and Reid (2014). "Stratospheric tropospheric profiler specifications" section discusses the ST systems, while "Stratospheric tropospheric profiler operation" section presents results and impacts of the profilers on numerical weather prediction.

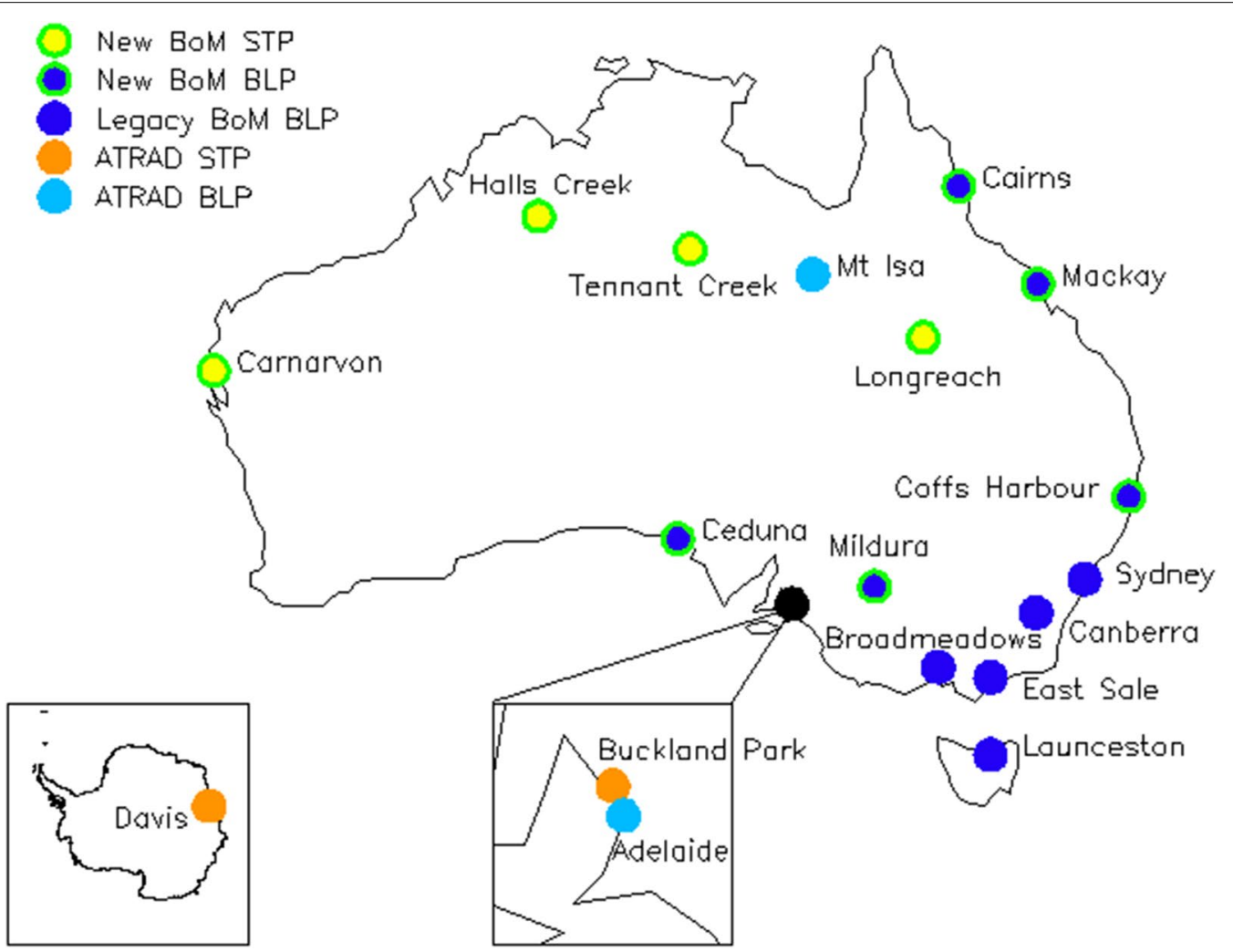

Fig. 1 The Australian Wind Profiler network 


\section{Stratospheric tropospheric profiler specifications}

As we noted above, the design goals for the STPs were for them to be:

- Robust and capable of operating in remote and harsh environments.

- Very low maintenance.

- Modular and scalable.

- Not be susceptible to single-point failures.

- To have commonality of hardware and software across both stratospheric tropospheric and boundary layer profiling systems.

Based on our experience with both spaced antenna (SA) and Doppler beam swinging (DBS) systems (see, e.g., Vincent et al. 1998; Morris et al. 2004; Reid et al. 2005; Reid 2009a, b; Dolman and Reid 2014), and the target height coverage, we opted for DBS operation. We selected an antenna array design of 144 Yagi antennas arranged on a $12 \times 12$ square grid, giving a beam width of about $7^{\circ}$, and phased to produce off-zenith beam directions of $15^{\circ}$, directed north, south, east and west, and also vertically. The antenna array grid spacing is $0.644 \lambda$ which means only three phase delays (repeated across the array) are required to phase the entire array appropriately for the selected off-zenith angle, and also that the spacing on the diagonal is less than one wavelength, so grating lobes are avoided.

The choice of an off-zenith angle of $15^{\circ}$ avoids the need to correct for the effect of the aspect sensitivity of the atmosphere on the beam look directions and was used previously with the NOAA VHF profilers installed across the Pacific (see, e.g., Gage et al. 1994). The overall basic system design was used for both the ATRAD Woomera VHF ST radar system (see, e.g., Reid 2009b), the Vaisala LAP-12,000 wind profiler installed for the UKMO in northern Scotland in collaboration with ATRAD (see, e.g., Winston 2004) and other LAP-12,000 systems installed in Brazil and China. These LAP-12,000 systems all use the ATRAD configuration and various ATRAD subsystems. The $64 \mathrm{MHz}$ UKMO system has since been upgraded to the build and software standard equivalent to the STPs discussed in this paper, but with a peak power of $40 \mathrm{~kW}$.

A schematic of the STP system is shown in Fig. 2. The system architecture is modular. The basic power amplifier (PA) delivers $4 \mathrm{~kW}$ peak power at a maximum $10 \%$ duty cycle. There are six PAs to a chassis, with two chassis in each of two racks. This yields a total power of $96 \mathrm{~kW}$ before combining. The outputs of the PAs are combined

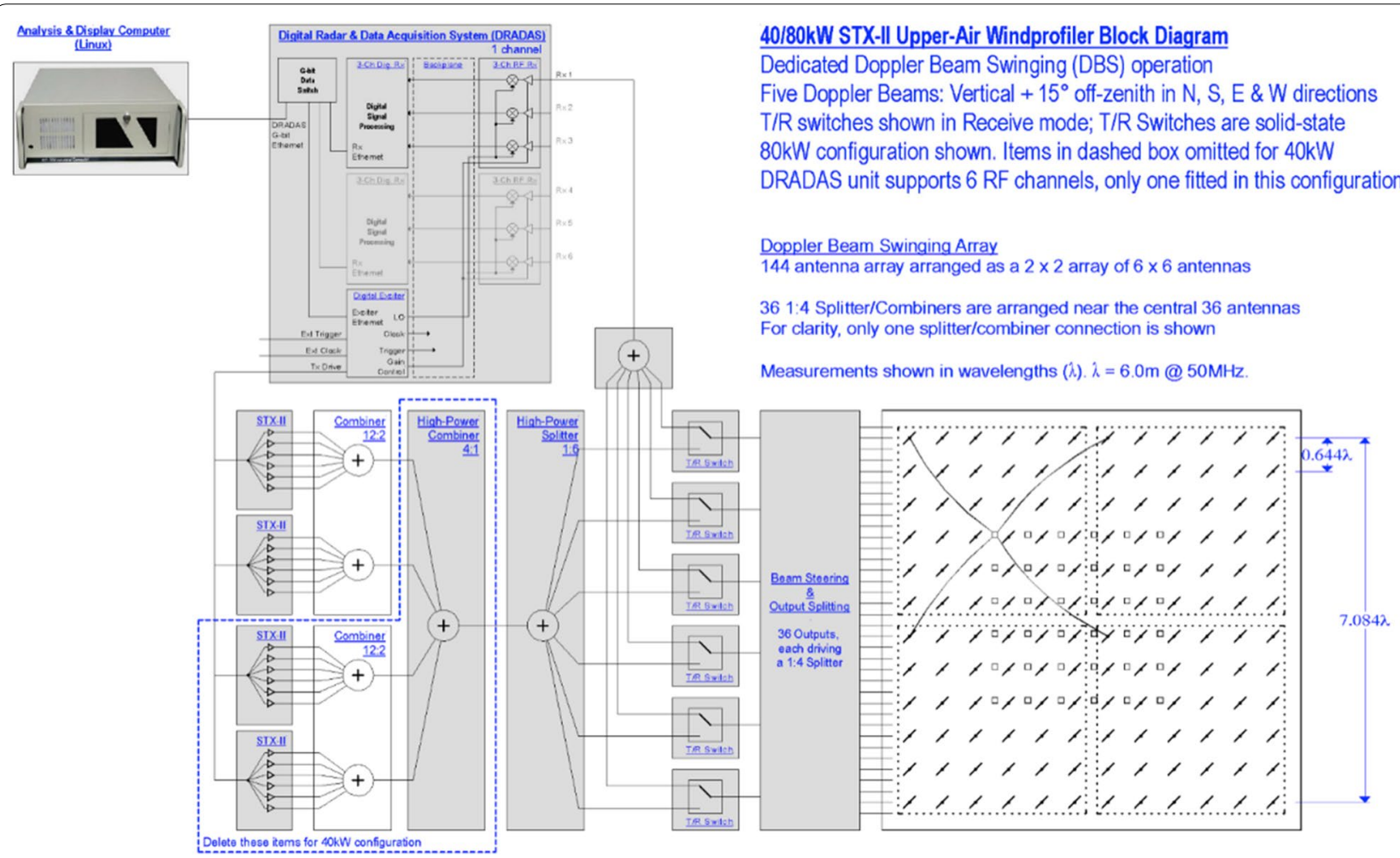

Fig. 2 Schematic of the ST profiler. The operational systems use the $80 \mathrm{~kW}$ configuration, while the BP ST radar discussed in the text uses the $40 \mathrm{~kW}$ configuration. See text for a fuller description 
up to one output before being split into six outputs and fed into six passive transmit/receive $(T / R)$ switches. This arrangement mitigates the effect of any single PA failure. It also significantly improves the low-level performance normally obtained by this class of radar, because passive $T / R$ switches switch faster than $T / R$ switches based on PIN diodes typically used in high-power ST systems. Using multiple switches alleviates the load on any particular T/R switch.

The outputs from the $T / R$ switches are fed into the beam steering unit during transmission and into a single receiver channel on reception. Beam steering is via relayswitched cable phase delays. Three receiver channels are available, but only one is used in this configuration. The digital receiver itself is based on a Virtex-4 FPGA. The system includes self-monitoring, and detailed system health information is available remotely. The technical specifications of the operational STPs are summarized in Table 1.

\section{Stratospheric tropospheric profiler operation}

In an operational environment such as a meteorological office, wind profiler data may both be presented to forecasters and ingested into models. There is also a growing trend for non-meteorologically trained personnel to utilize data from meteorological instruments, such as those in the mining, agricultural and aviation industries. In all cases, user demands for readily understandable qualitycontrolled wind data, with excellent spatial and temporal resolution, must be met. Low-level height coverage, that is retrieving good-quality winds from as close to the ground as possible, is of particular importance when larger antenna array sizes and high powers are employed. Addressing these issues for an operational STP system is the topics for the following discussion.
Throughout 2009 and 2010 an STP located at Buckland Park (BP), primarily used as a research and development system, was incrementally upgraded by ATRAD Pty Ltd (Dolman and Reid 2011a, b, c). The upgrade brought the instrument up to current ATRAD build standard and was done in conjunction with the University of Adelaide, who host the STP on their field site at BP, located $40 \mathrm{~km}$ north of the city of Adelaide, South Australia. Like the operational STPs, the BP STP is comprised of 144 Yagi antennas at half wavelength spacing, arranged on a 12 by 12 square grid, but operates with half of the operational peak power at $40 \mathrm{~kW}$. This is the only difference in build standard to the operational systems, which run at a peak power of $80 \mathrm{~kW}$, and thus achieve superior height coverage. The BP STP was used to verify the system concepts prior to the deployment of the first operational STP (Dolman and Reid, 2010, 2011a, c).

As we noted above, the STPs use the DBS approach to measure the line of sight Doppler shift in up to five beam directions, vertical plus $15^{\circ}$ off-zenith in the cardinal directions. As temporal resolution is important in most non-research settings, typical operation uses the vertical and two orthogonal beams to resolve the three-dimensional wind field, in interleaved low- and high-mode operation, resulting in six-minute resolution (1-minute dwell per beam). Table 2 gives typical operating parameters for low- and high-mode experiments.

As described above, the ST profilers complete a 3-beam low- and high-mode scan cycle every 6 min. The AGBoM has selected a 30-minute update cycle; thus, 5 low- and high-mode profiles are quality-controlled and averaged to produce low- and high-mode wind estimates. These low- and high-mode wind profiles are then converted to BUFR format and output to users, and in most cases data are also available on the Global Telecommunication System (GTS) and the EUMETNET website (http://eumet

Table 1 Technical specifications of the operational ST system

\begin{tabular}{|c|c|}
\hline Parameter & ATRAD operational STP \\
\hline Power & 80 kW (24 4 kW modules, i.e., 96 kW at the transmitter) \\
\hline Operating frequency & $55 \mathrm{MHz}$ \\
\hline Antenna configuration & 144 Yagi antennas, arranged in a $12 \times 12$ square grid. \\
\hline Radar receiver & One coherent (complex) radar receiver channel \\
\hline Data acquisition & Virtex-4 FPGA; 16-bit native digitization \\
\hline Analysis modes & Doppler \\
\hline Remote control & Remote monitoring and control via internet, Ethernet or dialup \\
\hline Data output & $\begin{array}{l}\text { ATRAD data format (raw and analyzed) and BUFR format (as } \\
\text { individual or averaged profiles) }\end{array}$ \\
\hline Sampling range & User configurable, suggested settings are from 0.2 to $20 \mathrm{~km}$ \\
\hline Range resolution & $\begin{array}{l}\text { User configurable from } 100 \text { to } 1200 \text { m. Standard settings are } \\
250 \text { m (low mode) and } 500 \text { m (high mode) }\end{array}$ \\
\hline
\end{tabular}


Table 2 Typical operating parameters for both lowand high-mode experiments

\begin{tabular}{lll}
\hline & STP low mode & STP high mode \\
\hline Pulse width & $250 \mathrm{~m}$ & $500 \mathrm{~m}$ \\
PRF & $14000 \mathrm{~Hz}$ & $6000 \mathrm{~Hz}$ \\
Range & $0-8 \mathrm{~km}$ & $1-20 \mathrm{~km}$ \\
Sampling interval & $100 \mathrm{~m}$ & $500 \mathrm{~m}$ \\
Dwell time & $55 \mathrm{~s}$ (per beam) & $55 \mathrm{~s}$ (per beam) \\
Coherent integrations & 700 & 150 \\
No. of spectral points & 1100 & 2200 \\
\hline
\end{tabular}

net.eu/activities/observations-programme/current-activ ities/e-profile/radar-wind-profilers/).

The quality control procedure is based on a technique following Weber and Wuertz (1991). The procedure for an AGBoM operational BL profiler is described in Dolman and Reid (2014), and the reader is referred here for a detailed description. While the BL description refers to quality control on magnitude and direction data, the algorithm was designed to operate on any gridded data set for which some similarity is expected, and can operate on the radial data set where available and preferred. Averaging in the radial domain offers greater height coverage performance over the approach of averaging in the wind domain and is thus utilized on the operational ST network. The algorithm considers the subset of either low- or high-mode temporal-spatial data to be averaged; thus, the data block consists of as many low-/ high-mode profiles collected at all acquisition heights in the averaging period, which for operational AGBoM profilers is 30 minutes. Regardless of operation on radial or wind data, the algorithm determines local neighborhoods around individual points, hereafter generically named "data," consisting of a minimum of 8 and a maximum of 24 points, dependent on location within the grid. The local neighborhood is calculated from up to two heights above and below the data point under consideration, and similarly two time stamps on either side. The "similarity" of the considered data point to each of its neighbors is then calculated, and those considered similar are used in a planar interpolation to generate an interpolated value of said data point. The original and interpolated values are then compared, and the original data point retained and considered "good" if this check is passed. This process is depicted graphically in Fig. 3.

Good data values are then considered, and some additional checks are performed to potentially re-include data which may have been rejected in the quality control process when, for example, a good data point falls within a neighborhood of outliers and is inadvertently rejected. The median profile of the good data is then calculated for each beam, and subsequently, a wind profile is calculated. The quality-controlled wind profiles are output to end users in low- and high-mode BUFR data streams in real time. All of the processing described above, from raw data collection to BUFR output, is completed on site on the radar PC, utilizing ATRAD proprietary software.

The configuration described above was tailored to AGBoM requirements. The algorithm design is more generic and can be modified to operate with continuous data sets, smaller/larger neighborhoods, and with variations in the 'good' determinants dependent on requirements. For completely outlier-free data, strict quality controls should be enforced, but this will be at the expense of some height coverage.

\section{Stratospheric tropospheric profiler results}

ST profilers were installed at Tennant Creek and Carnarvon in 2012, Halls Creek in 2015 and the final ST profiler of the new network in Longreach in 2017. Each installation was compared against co-located radiosondes, and zonal and meridional winds were required to meet a $\pm 0.3 \mathrm{~m} / \mathrm{s}$ shift in an aggregated line of best fit calculation. Profiler data were averaged to $30 \mathrm{~min}$, beginning from sonde launch time, and quality-controlled using the standard operating procedure described above. Sonde



Fig. 3 Reproduced from Dolman and Reid (2014). Graphical representation of the quality control process for a point within its local neighborhood. Part a shows a maximum neighborhood (blue) of 24 points surrounding point $x$ (purple). Part b shows the points which were deemed 'good' (green) and 'bad' (red). In c only the good points are used in a planar interpolation, to produce an interpolated value of point x (d). The original and interpolated values of point $x$ are then used to determine whether $x$ should be considered good or bad (e) 
data were averaged spatially to match the profiler range gate spacing in both low and high modes. No further attempts were made to remove inevitable outliers in the profiler data or errors in the sonde data. This procedure results in a single profiler and sonde data point for each sonde flight, at the range gate spacing of the profiler. All available data pairs were then used to calculate the line of best fit. Example comparisons in the zonal and meridional components from Halls Creek are shown in Fig. 4, and results from all ST installs, along with the number of sonde comparisons and distance between profiler and sonde launch location, are summarized in Table 3. Full results for all installs, including equivalent contour plots and individual flight comparisons, can be found in Dolman and Reid (2012a, b, c, 2015, 2017). Table 3 demonstrates that while the low modes are typically in good agreement, the high modes, and in particular the meridional component, show lower line of best fit statistics.
This has been investigated, and the standard deviation and variance are similar in both components and do not change with height. The difference is also not an effect of wind speed in either component; thus, it is not the result of poor meridional agreement when the sonde drifts with a stronger zonal wind. The meridional components are smaller, and so the error could come from either instrument attempting to measure near zero. A technique due to Hocking et al. (2001) allows the inclusion of uncertainties in measurements. Attributing errors of 0.15, 0.5, 1.0 and 2.0 to the sonde typically result in little change in the zonal direction but increasing agreement in the meridional component. This is potentially due to taking measurements near zero but warrants further investigation with GPS sondes where distance from launch location can also be considered.

Wind profile retrieval through as much of the atmosphere as possible is an important aspect of profiler
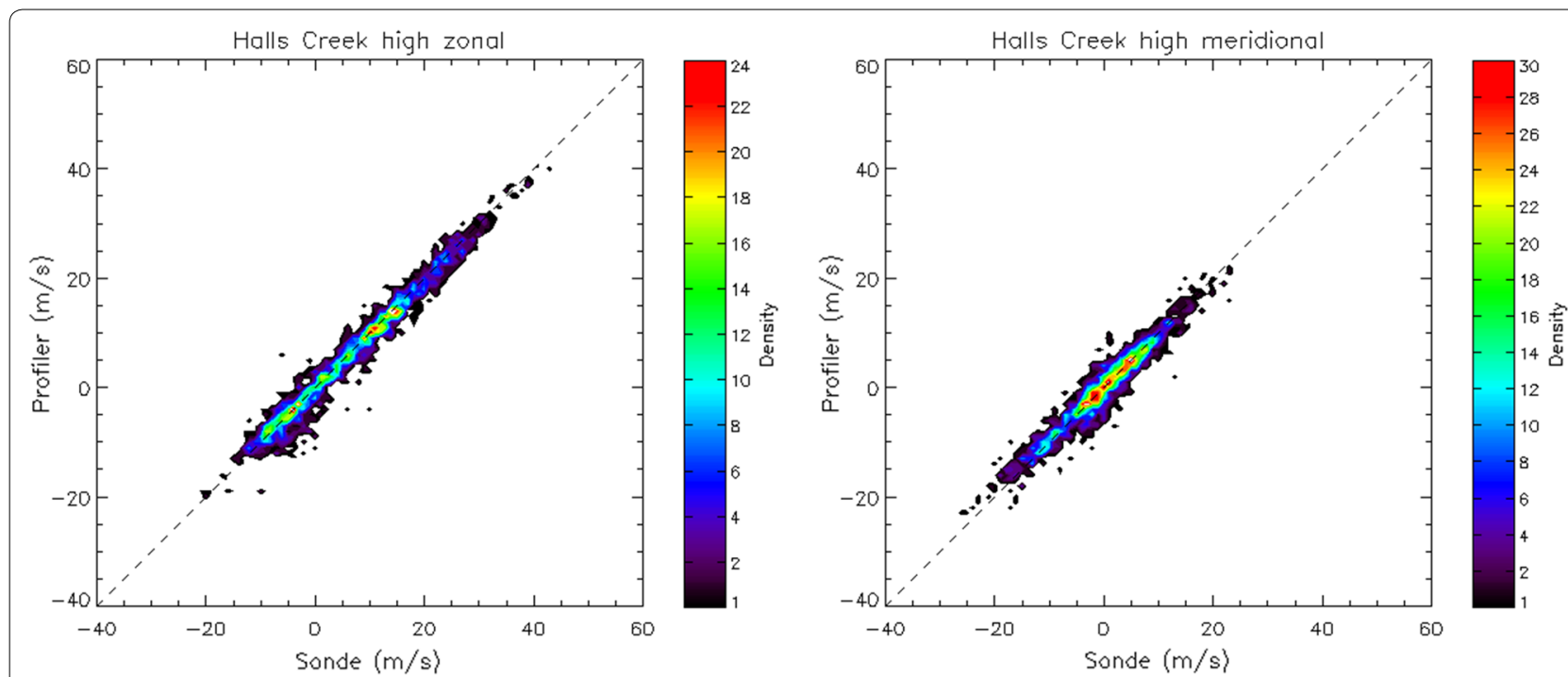

Fig. 4 Zonal (left) and meridional (right) colored contour wind comparisons from the Halls Creek profiler. The sonde data are shown on the $x$ axis, with the profiler data on the $y$ axis, and colors indicate data density

Table 3 ST profiler zonal and meridional wind comparisons

\begin{tabular}{|c|c|c|c|c|c|}
\hline Location & Number of sondes & Distance between sites & & Zonal line of best fit & $\begin{array}{l}\text { Meridional } \\
\text { line of best fit }\end{array}$ \\
\hline \multirow[t]{2}{*}{ Tennant Creek } & 62 & Co-located & Low & 1.00 & 0.97 \\
\hline & & & High & 0.96 & 0.93 \\
\hline \multirow[t]{2}{*}{ Carnarvon } & 58 & Co-located & Low & 1.00 & 1.00 \\
\hline & & & High & 0.97 & 0.93 \\
\hline \multirow[t]{2}{*}{ Halls Creek } & 100 & $\sim 500 \mathrm{~m}$ & Low & 0.97 & 0.93 \\
\hline & & & High & 0.97 & 0.93 \\
\hline \multirow[t]{2}{*}{ Longreach } & 45 & $\sim 100 \mathrm{~m}$ & Low & 0.97 & 0.95 \\
\hline & & & High & 0.97 & 0.93 \\
\hline
\end{tabular}


operation. As operational profilers output 30-minute averaged winds, 48 possible profiles across a day, per height, were calculated to examine the percentage height coverage of each operational profiler. Figures 5 and 6 show these calculations for low and high modes, respectively, color-coded by percentage, for the Tennant Creek profiler from its installation date on December 13, 2011. Cells colored light green indicate $100 \%$ data availability, while dark green show $90-99 \%$. Black cells show $2 \%$ availability, which is used as an indication of profiler performance against the typical practice of launching sondes twice daily. White cells indicate no data were available. Figure 5 demonstrates excellent height coverage, with most of the plot in green indicating more than $90 \%$ of data were available, and a good proportion of these data are light green at 100\% availability. Figure 6 shows excellent height coverage to around $12 \mathrm{~km}$, a drop-off around $20 \%$ above this and then excellent returns at the tropopause.

Retrieving profiles from as close to the ground as possible is also very important and has traditionally been a problem for large footprint antennas. Through an incremental improvement process with an emphasis on minimizing internal clutter, these operational profilers typically retrieve useable data from 2 times the pulse length. This is illustrated in Fig. 5, where little data return is seen in the first range gate, while most data from the second range gate have passed quality control procedures and been retained. Returns at these low heights are within the near field of the profiler and indicate that

accurate estimates are possible before the far-field beam has been fully formed. Furthermore, these low-level results have been compared to radiosonde data using the method described above and shown to be accurate (Dolman and Reid 2010).

\section{Australian wind profiler network in NWP}

Data from the Australian Wind Profiler network are available on the GTS, and they are assimilated into all major operational global numerical weather prediction (NWP) systems. Measuring the impact of any instrument on NWP forecast skill is challenging, time-consuming and generally computationally expensive, particularly to run data denial experiments. Regardless, investigations are important in optimizing network performance and also in funding schemes, generating the best outcome for expenditure. Examples of previous studies include Eyre and Reid (2014), Lee et al. (2013) and Illingworth et al. (2015).

The Australian Government Bureau of Meteorology utilizes a relatively new forecast error reduction determination technique. Here the effects of data assimilation on forecast error reduction in a 24-hour global NWP forecast can be split up and attributed to individual observations (Lorenc and Marriott 2014). Over time, this technique permits the aggregation and comparison of the reduction in forecast error due to components such as observing systems, instruments or groups of instruments, that is, the technique can quantify the impact all assimilated observations halve on reducing the forecast error. This technique can either be applied using a global measure of forecast error, or with the error measure restricted to the Australian region.

Figure 7 shows the impacts of the upper air network, aggregated from February 15 to May 24, 2016, with the error measure restricted to the Australian region. Radiosondes (TEMP) which include pressure, temperature and humidity data in addition to winds are represented as squares, wind only tracked balloons (PILOT) as circles and wind profilers (WINPRO) as triangles. Reductions in the forecast error are represented by the color scale, where cooler colors represent negative impacts, that is, a reduction in the forecast error, and are thus desirable. Of the profiler stations, Halls Creek, Carnarvon, Tennant Creek and Ceduna have the most significant negative impact. This is likely due to (a) height coverage, as other than Ceduna, these are ST profilers and are thus sampling roughly twice the atmosphere when compared to the Ceduna BLP, (b) remoteness of these stations; it is a consistent global finding (Cress and Wergen

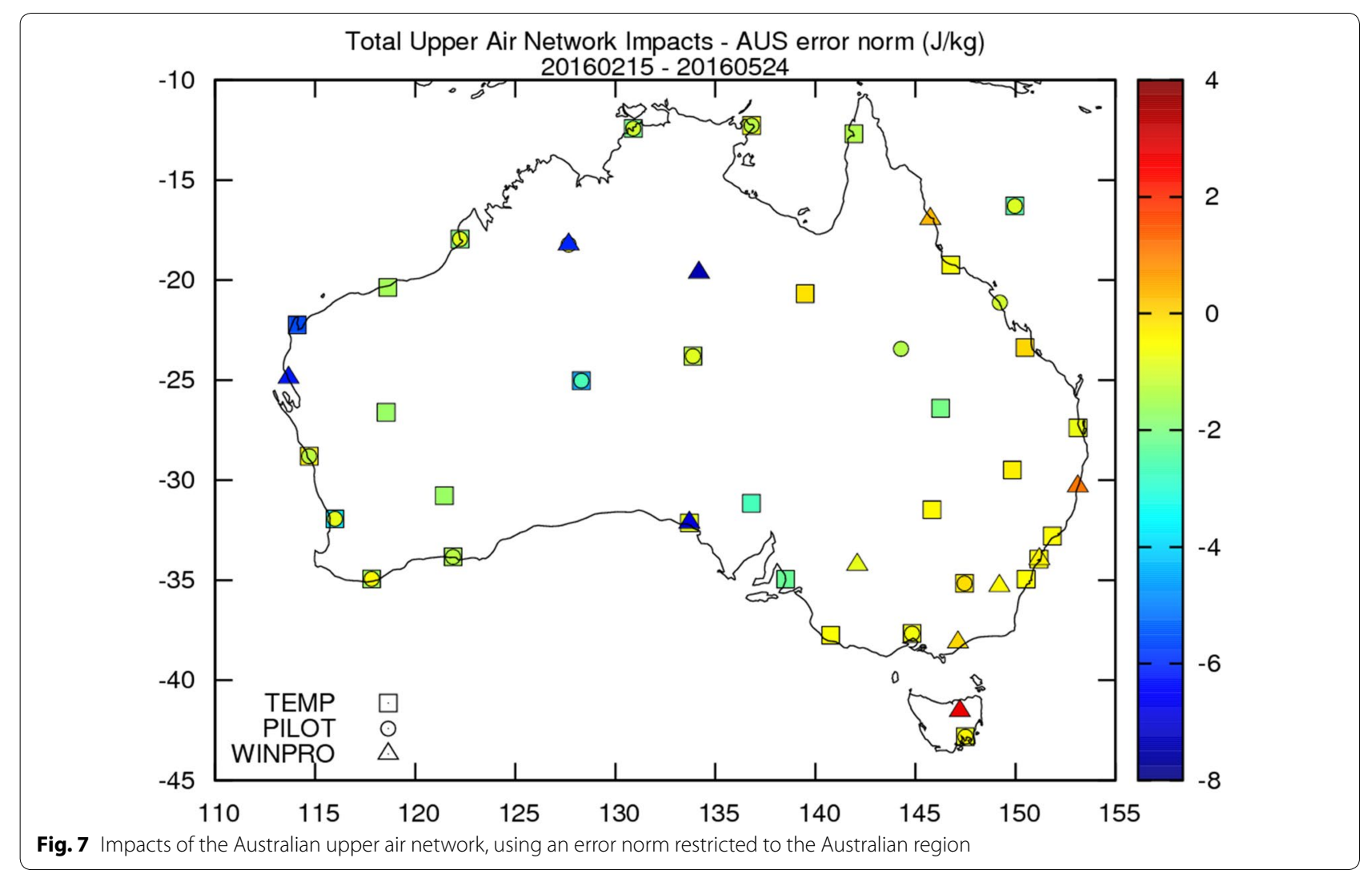


2001; Seaman 2007) that more remote stations have high impact per observation in NWP assimilation, and (c) the prevailing weather pattern across Australia is from west to east, and the general trend on the map across all observation systems shows more negative impacts in the west. The legacy systems in Sydney, Canberra and East Sale show zero impact, that is they are not decreasing forecast error, but are not adding to it either. This may be related to only assimilating data to $2 \mathrm{~km}$, which is minimal compared to both the newer systems and sondes but may also be related to location. The Mildura BL also shows neutral impact. Cairns, Coffs Harbour and Launceston (Launceston is a legacy system) show positive impacts, which are not ideal and warrant further investigation: the relatively short 3-month period of these results leaves open the possibility that the impacts may vary seasonally.

\section{Summary}

The continuous development of large footprint and higher power wind profiling radars operating at VHF has led to systems capable of sampling from near ground to the tropopause. These $80 \mathrm{~kW} 144$ antenna ST systems are used by the Australian Government Bureau of Meteorology in regions where upper levels are required. ST radars measure winds using the traditional Doppler beam swinging approach, and data quality control then ensures averaged data are largely outlier free. Australian wind profiler data are ingested into global NWP models and have been subject to multiple studies measuring the data impact on forecast error reduction. The Australian Government Bureau of Meteorology measures forecast error reduction in a 24-hour global NWP forecast due to data assimilation, with the ability to split out individual observations. Preliminary results suggest profilers in more remote locations have the highest impact per NWP observation, and there is also a trend following the prevailing Australian weather pattern, where profilers on the west coast have a higher impact than those on the east.

\section{Conclusion}

STPs using the DBS system are used by the Australian Government Bureau of Meteorology to measure winds from near ground to the tropopause in Tennant Creek, Halls Creek, Carnarvon and Longreach. These STPs are part of a network of 14 operational systems and a larger network of 19 operational/research systems across Australia. The STP systems deliver quality-controlled winds in BUFR format to both Australian forecasters and are ingested into global NWP models. Initial results suggest the STPs have a high impact per observation on forecast error reduction.

\section{Abbreviations}

AGBoM: Australian Government Bureau of Meteorology; BL/BLP: boundary layer/boundary layer profiler; BP: Buckland Park; BUFR: Binary Universal Form for the Representation of meteorological data; DBS: Doppler beam steering; FCA: full correlation analysis; GTS: global telecommunication system; ST/STP: stratosphere-troposphere/stratospheric tropospheric profiler; VHF: very high frequency; WPR: wind profiling radar.

\section{Authors' contributions}

BKD and IMR conducted the research presented in this paper, largely comparing radiosonde to profiler observations. BKD prepared the majority of this manuscript. CT conducted the NWP impact research and prepared Fig. 7 and edited the NWP section of this manuscript. All authors read and approved the final manuscript.

\section{Author details}

${ }^{1}$ ATRAD Pty Ltd, Thebarton, Australia. ${ }^{2}$ The University of Adelaide, Adelaide, Australia. ${ }^{3}$ Australian Government Bureau of Meteorology, Docklands, Australia.

\section{Competing interests}

IMR is Executive Director and BKD is Senior Scientist at ATRAD Pty Ltd, which manufactured the radars used in this study. CT is employed by the AGBoM who funded the operational network.

\section{Availability of data and materials}

Please contact the author for data requests

\section{Funding}

The network is funded under contract \#055/2008, and the NWP impact research was funded by the AGBOM. Funding for the remainder of the research was provided by ATRAD Pty Ltd. The involvement of BKD and IMR was supported by ATRAD Pty Ltd. Operational profilers form part of the Australian Government Bureau of Meteorology Surface Based Systems Network.

\section{Publisher's Note}

Springer Nature remains neutral with regard to jurisdictional claims in published maps and institutional affiliations.

Received: 22 March 2018 Accepted: 22 October 2018

Published online: 29 October 2018

\section{References}

Cress A, Wergen W (2001) Impact of profile observations on the German Weather Service's NWP system. Meteorol Z 10:91-101

Crochet M, Bourdier C, Spano E (1993) VHF ST radar for low altitude investigations. In: National Central Univ., Solar-Terrestrial Energy Program: Proceedings of the 6th workshop on technical and scientific aspects of MST Radar, 128-131 (SEE N96-17458 04-32)

Dolman BK, Reid IM (2010) Buckland Park STP low-level performance, ATRAD Science Report, Doc ASR 15-70004-public, 17 pp, October 19, http:// dx.doi.org/10.13140/RG.2.2.23461.60644

Dolman BK, Reid IM (2011a) Buckland Park BLP Historical Evaluation version 1.0, ATRAD Science Report, Doc No. 15-70016-1, ASR 3-2011, 20 pp, June 3, 2011, http://dx.doi.org/10.13140/RG.2.2.22805.01765

Dolman BK, Reid IM (2011b) ST IOP Report part 1 version 1.0, ATRAD Science Report, Doc No. 15-70021-1, ASR 5a-2011, 107 pp, August 12, http:// dx.doi.org/10.13140/RG.2.2.14935.37284

Dolman BK, Reid IM (2011c) ST IOP Report part 2 version 1.0, ATRAD Science Report, Doc No. 15-70021-2, ASR 5b-2011, 85 pp, August 25, http://dx.doi. org/10.13140/RG.2.2.14699.44324

Dolman B, Reid I (2012a) Tennant Creek STP SAT + 1 Month Analysis version 1.0, ATRAD Science Report, Doc No. 15-70027-1, ASR 1a-2012, 34 pp, 14 February

Dolman B, Reid I (2012b) Tennant Creek STP SAT + 1 Month Analysis Height Coverage Supplement version 1.0, ATRAD Science Report, Doc No. 15-70027-2, ASR 1b-2012, 37 pp, 14 February 
Dolman B, Reid I (2012C) Carnarvon STP SAT + 1 Month Analysis version 1.0, ATRAD Science Report, Doc No. 15-70030, ASR 2-2012, 71 pp, 2 October

Dolman B, Reid I (2013) Rainfall studies using co-located VHF and UHF wind profiling radars, Radar (Radar), 2013 international conference on, 315,317, http://dx.doi.org/10.1109/RADAR.2013.6652005

Dolman BK, Reid IM (2014) Bias correction and overall performance of a VHF spaced antenna boundary layer profiler for operational weather forecasting. J Atmos Solar Terr Phys 45:526. https://doi.org/10.1016/j.jastp .2014.02.009i

Dolman B, Reid I (2015) Halls Creek STP SAT + 1 Month Analysis version 1.0, ATRAD Science Report, Doc No. 15-70053, ASR 1-2015, 99 pp, 25 November

Dolman B, Reid I (2017) Longreach STP SAT + 1 Month Analysis version 1.0, ATRAD Science Report, Doc No. 15-70057, ASR 1-2017, 58 pp, 24 April

Ecklund WL, Carter DA, Balsley BB (1988) A UHF wind profiler for the boundary layer: brief description and initial results. J Atmos Ocean Technol 5:432-441

Eyre J, Reid R (2014) Cost-benefit studies for observing systems, Forecasting Research Technical Report No: 593, http://www.metoffice.gov.uk/media/ pdf/k/n/FRTR593.pdf

Gage KS, McAfee JR, Ecklund WL, Carter DA, Williams CR, Johnston PE, Riddle AC (1994) The christmas island wind profiler: a prototype VHF wind-profiling Doppler radar for the tropics. J Atmos Ocean Technol 11:22-31. https ://doi.org/10.1175/1520-0426(1994)011\%3c0022:TCIWPA\%3e2.0.CO;2

Hocking WK, Thayaparan T, Franke SJ (2001) Method for statistical comparison of geophysical data by multiple instruments which have differing accuracies. Adv Space Res 27:1089-1098

Illingworth AJ, Cimini D, Gaffard C, Haeffelin M, Lehmann V, Löhnert U, O'Connor EJ, Ruffieux D (2015) Exploiting existing ground-based remote sensing networks to improve high-resolution weather forecasts. Bull Am Meteorol Soc 96:2107-2125. https://doi.org/10.1175/BAMS-D-13-00283.1

Lee J, Le Marshall J, Tingwell C, Roux B (2013) Impact of satellite observations on southern hemisphere forecasts from the operational ACCESS-G NWP model. CAWCR Res Lett 10:27-33

Lorenc AC, Marriott RT (2014) Forecast sensitivity to observations in the Met Office Global numerical weather prediction system. Q J R Meteorol Soc 140:209-224. https://doi.org/10.1002/qj.2122
Morris RJ, Murphy DJ, Reid IM, Holdsworth DA, Vincent RA (2004) First polar mesosphere summer echoes observed at Davis, Antarctica $\left(68.6^{\circ} \mathrm{S}\right)$. Geophys Res Lett 31:L16111. https://doi.org/10.1029/2004GL020352

Reid IM (2009a) Final Report on the Mount Gambier Wind Profiler Project, ATRAD Science Report, ASR01-2009, 15 pp, 7 April, http://dx.doi. org/10.13140/RG.2.2.25321.60007

Reid IM (2009b) A note on the woomera wind profiler project, ATRAD Science Report, ASR02-2009, 9 pp, 7 April, http://dx.doi.org/10.13140/ RG.2.2.32086.14408

Reid IM, Dolman BK (2010) Buckland Park BLP Bias Report version 1.0, ATRAD Science Report, Doc No. 15-7-0005, ASR 1-2010, 34 pp, October 19, http://dx.doi.org/10.13140/RG.2.2.26160.46083

Reid IM, Holdsworth DA, Kovalam S, Vincent RA, Stickland J (2005) The Mount Gambier VHF wind profiler, Radio Sci., 40, RS5007, http://dx.doi. org/10.1029/2004RS003055

Sato T, Doji H, Iwai H, Kimura I, Fukao S, Yamamoto M, Tsuda T, Kato S (1990) Computer processing for deriving drop-size distributions and vertical air velocities from VHF Doppler radar spectra. Radio Sci 25(5):961-973

Seaman RS (2007) Which Australian rawinsonde stations most influence wind analyses? Aust Meteorol Mag. 56:285-289

Vincent RA, May PT, Hocking WK, Elford WG, Candy BH, Briggs BH (1987) First results with the Adelaide VHF radar: spaced antenna studies of tropospheric winds. J Atmos Terres Phys 49:353-366. https://doi. org/10.1016/0021-9169(87)90030-4

Vincent RA, Dullaway S, Mackinnon A, Reid IM, Zink F, May PT, Johnson BH (1998) A VHF boundary layer radar: first results. Radio Sci 33:845-860. https://doi.org/10.1029/98RS00828

Weber BL, Wuertz DB (1991) Quality control algorithm for profiler measurements of winds and temperatures. NOAA Tech. Memo. ERL WPL-212, 32 pp. [NTIS PB92124080XSP.]

Winston $\mathrm{H}$ (2004) Vaisala wind profilers support: modernization of upper-air data collection network in the UK. Vaisala News 164:24-25

\section{Submit your manuscript to a SpringerOpen ${ }^{\circ}$ journal and benefit from:}

- Convenient online submission

- Rigorous peer review

- Open access: articles freely available online

- High visibility within the field

- Retaining the copyright to your article

Submit your next manuscript at $\boldsymbol{\nabla}$ springeropen.com 